\title{
Experimental Assessment of Turbulence Convective Heat Transfer and Pressure Drop in Annuli using Nanoporous Graphene Non-Newtonian Nanofluid
}

\author{
Shahin Ghanbari - Kourosh Javaherdeh* \\ University of Guilan, Faculty of Mechanical Engineering, Iran
}

\begin{abstract}
In the current research work, turbulence convective heat transfer coefficient enhancement and pressure drop of nanoporous graphene non-Newtonian nanofluid were investigated in an annular tube in the developing region. The nanofluid was prepared by using nanoporous graphene in different concentrations of $0.05 \mathrm{wt} . \%, 0.1 \mathrm{wt} . \%$, and $0.2 \mathrm{wt} \%$ in an aqueous solution of carboxyl methyl cellulose (CMC). All thermophysical and rheological characteristics were evaluated, and pseudo-plastic (shear-thinning) rheological behaviour was observed for all samples. The results revealed that adding $0.2 \mathrm{wt}$.\% nanoporous graphene to the base fluid leads to $12.4 \%$ and $39.4 \%$ enhancement of thermal conductivity and heat transfer coefficient, respectively. This enhancement trend was almost linear for the concentrations lower than 0.1 wt.\% after which the enhancement rate was reduced significantly. Moreover, the results showed that when 0.05 and 0.1 wt.\% nanoporous graphene was adopted, the thermal performance factor (TPF) was increased by $8.7 \%$ and $16.7 \%$, respectively, and doubling the nanoparticle concentration from $0.1 \mathrm{wt}$ \% to $0.2 \mathrm{wt}$ \% could not augment the TPF; however, considering the assessed pressure drop, it also decreased it by $2.5 \%$. The increase of the Reynolds number led to an increase in heat transfer coefficient of all samples.
\end{abstract}

Keywords: nanoporous graphene; nanofluid; annular tube; thermal performance factor; pressure drop

Highlights

- $\quad$ Non-Newtonian flow and convective heat transfer characteristics were experimentally investigated through an annular tube.

- $\quad$ Thermal and hydrodynamic performances of turbulent flow in the annular tube were investigated for different concentrations of the non-Newtonian nanofluid.

- $\quad$ Results showed that the thermal and hydrodynamic performances were improved with an increase in the concentration of the non-Newtonian nanofluid.

\section{INTRODUCTION}

In designing equipment such as heat exchangers, heating and cooling systems, it is of great importance to provide higher convective heat transfer coefficients. Techniques aimed at enhancing heat transfer can increase the thermal efficiency of such industrial devices while minimizing the cost and size. One of the solutions specified for this problem is the utilization of nanomaterials. To prepare nanofluids, nanoparticles are dispersed in an appropriate base solution which forms a suspension [1] to [3].

The initial works on the formation of nanofluids were concentrated on using metal and metal oxide nanomaterials [4]. In this respective, Heris et al. [5] researched the effect of using $\mathrm{Al}_{2} \mathrm{O}_{3}$ /water nanofluid on convective heat transfer from which it was found that by adopting 2.5 vol. $\%$ to 3 vol.\% nanoparticles, the maximum increment of heat transfer is acquired. In another research, Patel et al. [6] showed that when a mixture of $11 \% \mathrm{Au}$ and $\mathrm{Ag}$ nanoparticles are used, thermal conductivity is augmented by about $21 \%$. Moreover, as reported by Zarringhalam et al. [7], by using $\mathrm{CuO} /$ water nanofluid in forced turbulent convection in two uniaxial tubes, heat transfer is increased by up to $57 \%$ for the sample containing 2 vol.\% nanoparticles. In addition, in some relative reviews [8] to [10], thermophysical properties of different nanofluids were compared and discussed, and the effect of each nanofluid on heat transfer capability of the industrial equipment was studied. In different studies, convective heat transfer of various nanofluids has been investigated in laminar [11] and [12] and turbulent [13] flow regimes.

After using the metal and metal oxides, researchers started to use carbonaceous nanomaterials, which possessed higher thermal conductivity [14] and [15]. Among these efforts, Amrollahi et al. assessed the effect of multiwall carbon nanotubes on the convective heat transfer coefficient in laminar and turbulent flows [16]. For 0.1 wt.\% nanoporous graphene in a circular tube, $34 \%$ increment of convective heat transfer was obtained by Naghash et al. [17] in which the laminar flow regime was considered. Moreover, Amiri et al. [18] studied the thermophysical properties of the nanofluid prepared with functionalized graphene. They showed that the ethylene glycol-functionalized graphene in the mixed solution of water and ethylene glycol, the thermal conductivity was enhanced by 
up to $0.2 \mathrm{~W} /(\mathrm{m} \cdot \mathrm{K})$ for the $0.2 \mathrm{wt} . \%$ nanoparticles in comparison to the base solution.

Additionally, Askari et al. [19] investigated two different carbon nanostructures, including multiwalled carbon nanotubes and nanoporous graphene to prepare water-based stable nanofluids. They used the carbonaceous nanofluids in the cooling tower and showed that 0.1 wt. $\%$ multi-walled carbon nanotubes (MWCNT) and nanoporous graphene increased the cooling range by up to $40 \%$ and $67 \%$, respectively. Graphene oxide has also been utilized for this purpose by Ranjbarzadeh et al. [20]. In their study, different concentrations of graphene oxide were considered in a turbulent regime through an isothermal pipe. They have reported the maximum thermal performance coefficient of 1.148 for the sample possessing 0.1 vol.\% graphene oxide.

A vast number of studies on nanofluids have supported the idea that the rheology of nanofluid is more probably to be non-Newtonian fluid for which simplified Newtonian model is suitable for some studies [21]. For instance, Newtonian and nonNewtonian approaches were compared by Behroyan et al. [22] to assess the numerical Nusselt number for the nanofluid, which was prepared by 1.6 vol.\%. From this study, it was shown that the non-Newtonian model provides a more precise Nusselt number compared to that of the Newtonian model. Additionally, Hojjat et al. [23] investigated the properties of different metal oxides in a non-Newtonian shear thinning base fluid; they varied the nanoparticle concentration and temperature and used carboxyl methyl cellulose (CMC) as the pseudoplastic base fluid. By using highly pure graphene nanoparticles, Kole and Dey [24] studied the thermal conductivity, viscosity, and electrical conductivity of nanofluids, which were formed by using EG-distilled water as the base solution. In that research, for the prepared nanofluid and also the base solution, non-Newtonian behaviour was observed in which the nanofluid viscosity was increased by $100 \%$ in comparison to the base fluid.

In addition, there have been studies on the application of nanofluids in the annular passage for better thermal performance due to uses of this geometry in different industries [25]. In this context, a numerical investigation on the fluid flow and convective heat transfer of non-Newtonian nanofluid was carried out by Bahiraei et al. [26] in annuli, for which, also a neural network was developed to anticipate the convective heat transfer coefficient. In addition, El-Kaddadi et al. [27] studied the heat storage by the nanofluid prepared by $\mathrm{TiO}_{2}$ nanoparticles in an annular space, where the convective heat transfer was improved by increasing the nanoparticle concentration. Arzani et al. numerically and experimentally investigated the thermal performance of the MWCNTs and functionalized graphene nanoplatelet in an annular heat exchanger. They showed that the carbon-based nanostructures can provide better performance in heat transfer in this geometry [28] and [29]

In the literature, researchers have carried out only a few studies on the properties of carbonaceous non-Newtonian nanofluids in annuli; however, in this paper, the convective heat transfer coefficient of nanofluids of nanoporous graphene at different concentrations is evaluated experimentally in an annular tube in turbulence flow regime. For this end, at first, the base fluid and nanofluids of nanoporous graphene were prepared with different concentrations, and in the following, all thermophysical and rheological properties were evaluated. Then, thermal performance enhancement considering the pressure drop in the system in comparison to the base fluid was assessed under constant heat flux and at different Reynolds numbers. In this regard, along with the preparation of highly efficient nanofluid for thermal applications, the optimum nanoporous graphene content was also determined.

\section{MATERIALS AND METHODS}

The nanoporous graphene was purchased from the Research Institute of the Petroleum Industry (RIPI, Tehran, Iran) which was synthesized via special chemical vapour deposition (CVD) technique and possessed high pore volume $\left(2.11 \mathrm{~cm}^{3} / \mathrm{g}\right)$ and large specific surface area $\left(814 \mathrm{~m}^{2} / \mathrm{g}\right)$ and narrow pore size distribution [17] and [30]. The scanning electron microscopy (SEM) and Transmission electron microscopy (TEM) images of the used nanoporous graphene are represented in Fig. 1 in which the highly porous nature of the graphene is evident.

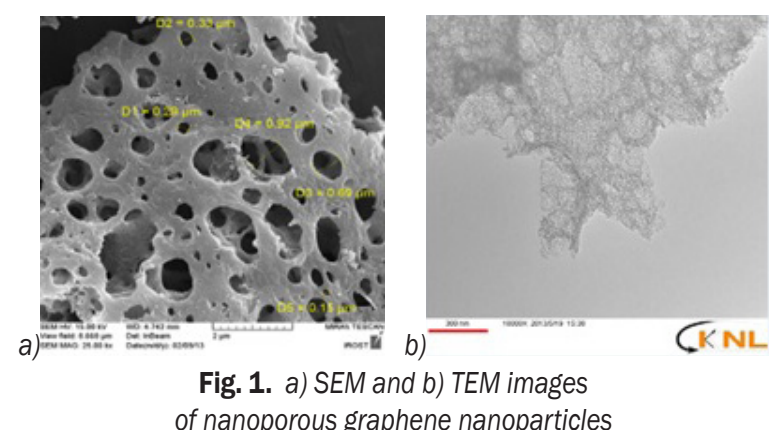

In the procedure of forming the nanofluids, the nanoporous graphene nanoparticles were dispersed 
in distilled water (DI) water and the $\mathrm{CMC}$ (with a nominal molecular weight of $900,000 \mathrm{~g} / \mathrm{mol}$ and a degree of substitution (DS) of 0.8 to 0.95 by Dae-Jung company, South Korea) was utilized as the surfactant in $0.2 \mathrm{wt} . \%$. Dispersion of the nanoparticles to prepare a uniform nanofluid was performed through the physical method by ultrasonic device for $4 \mathrm{~h}$, and a low-speed magnetic stirrer was employed to ensure the homogeneity of the base fluid (DI water and 0.2 wt. \% CMC) for $30 \mathrm{~min}$. Although the addition of 0.2 wt. \% CMC increases the duration of using an ultrasonic device compared to other surfactants, its bubbling effects are negligible, especially at high Reynolds numbers, and provides acceptable stability in the required experiments. To investigate the thermal performance of nanoporous graphene in annuli, suspensions with concentrations of 0.05 wt. $\%, 0.1$ wt. $\%$ and 0.2 wt. $\%$ were prepared and labelled as NPG-0.05, NPG-0.1, and NPG-0.2, respectively. Fig. 2 shows the nanofluid which was prepared by using 0.2 wt.\% nanoporous graphene. For minimizing the problems related to potential clustering and sedimentation of nanoparticles, a new nanofluid was formed and used immediately in each test.

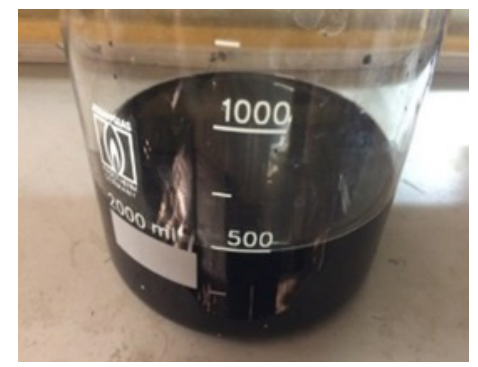

Fig. 2. The nanofluid sample which was prepared by using 0.2 wt. \% nanoporous graphene, 0.2 wt.\% CMC and DI water labelled as NPG-0.2

Fig. 3 gives the apparent viscosity $(\eta)$ of the base fluid and nanofluids which were prepared by different concentrations as a function of shear rate $(\gamma)$ at $25^{\circ} \mathrm{C}$. These have been measured by oscillatory and rotational rheometers (MCR 301 by Anton Par, Graz, Austria) with an accuracy of $\pm 2 \%$. As is clear from Fig. 3, by increasing the shear rate, apparent viscosity is decreased for all samples which indicate that all samples were of typical non-Newtonian fluids with shear thinning behaviour $(n<1)$ [31]. Moreover, the increase in the concentration of the nanoparticles has led to the enhancement of apparent viscosity.

The non-Newtonian behaviour of the samples can be explained by using the power law rheological model. The power law model is expressed in Eq. 1:

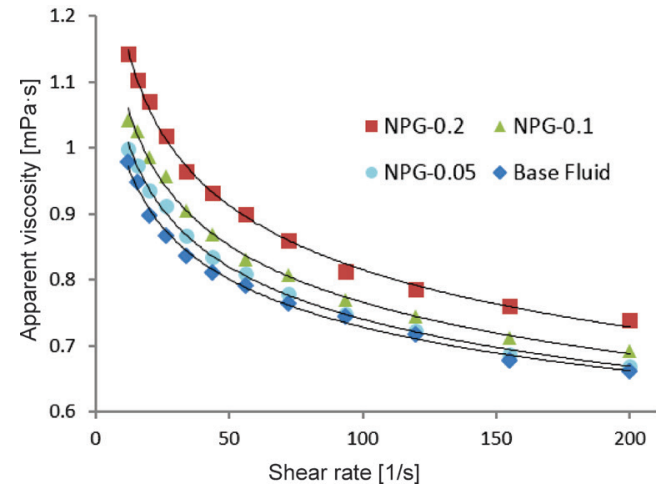

Fig. 3. Apparent viscosity of samples as a function of shear rate at $25^{\circ} \mathrm{C}$

$$
\eta=m \gamma^{n-1}
$$

In Eq. (1), two parameters exist in terms of flow consistency index $(m)$ and the flow behaviour index $(n)$ which have been calculated considering the trend of apparent viscosity as a function of shear rate at $25^{\circ} \mathrm{C}$, which are given in Table 1 . The heat capacity of the samples was measured by the calibrated differential scanning calorimeter (DSC-111, Setaram, France). Moreover, to calculate the density, a densitometer with an accuracy of $\pm 0.0001 \mathrm{~g} / \mathrm{cm}^{3}$ was used, and the thermal conductivity was measured by employing KD2 Pro (Decagon Device, Inc., USA) with an accuracy of $\pm 5 \%$, which is tabulated in Table 1. Furthermore, to keep the temperature constant within the limit of $\pm 0.1^{\circ} \mathrm{C}$, all measurements were performed three times in a bath with constant temperature, and average values are reported.

Table 1. Specification of the samples at $25^{\circ} \mathrm{C}$

\begin{tabular}{lcccc}
\hline Sample & $\begin{array}{c}\text { Flow } \\
\text { consistency } \\
\text { index, } \\
m\end{array}$ & $\begin{array}{c}\text { Flow } \\
\text { behaviour } \\
\text { index, } \\
n\end{array}$ & $\begin{array}{c}\text { Heat } \\
\text { capacity, } \\
C_{p} \\
{[\mathrm{~J} /(\mathrm{kg} \cdot \mathrm{K})]}\end{array}$ & $\begin{array}{c}\text { Density, } \rho \\
{\left[\mathrm{kg} /\left(\mathrm{m}^{3}\right)\right]}\end{array}$ \\
\hline Base fluid & 0.001369 & 0.863 & 4181.2 & 997.1 \\
\hline NPG 1 & 0.001456 & 0.853 & 4104.8 & 997.3 \\
\hline NPG 2 & 0.001560 & 0.845 & 4043.4 & 997.6 \\
\hline NPG 3 & 0.001725 & 0.837 & 3955.0 & 998.7 \\
\hline
\end{tabular}

Thermal conductivity is one of the most effective parameters that have a significant contribution to the enhancement of heat transfer coefficient [32]. Fig. 4 presents the thermal conductivity of samples in temperature ranges of $20^{\circ} \mathrm{C}$ to $45^{\circ} \mathrm{C}$. As expected, the thermal conductivity of samples in all concentrations was increased by raising the temperature [33]. This is due to weakening of interparticle and intermolecular 
adhesion forces at higher temperatures, which results in an increase of the Brownian motion of the particles. In addition, increasing the concentration of the nanoparticles could improve the thermal conductivity of the samples at all considered temperatures; for example, at $25{ }^{\circ} \mathrm{C}$ the increment of the thermal conductivity was $4.8 \%, 9.3 \%$, and $12.4 \%$ for the samples containing 0.05 wt. $\%, 0.1$ wt. $\%$, and 0.2 wt. $\%$ nanoparticles compared to that of the base fluid. However, this increment rate showed a decreasing trend at higher concentrations, which can be attributed to the saturation of the base fluid.

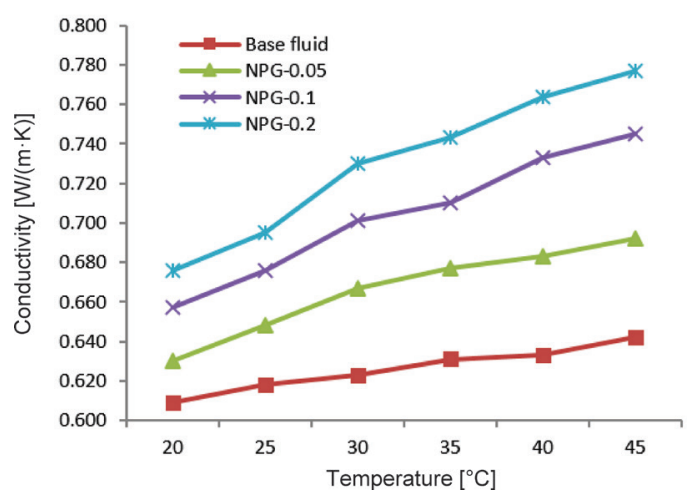

Fig. 4. The measured thermal conductivity of the prepared nanofluids and the base solution in the temperature range of $20^{\circ} \mathrm{C}$ to $45^{\circ} \mathrm{C}$

\section{EMPIRICAL SETUP AND METHODOLOGY}

Fig. 5 shows the equipment that has been utilized in the experimental study of the annulus convective heat transfer. The apparatus is composed of a flow loop, which included an annular tube, a container of fluid, a gear pump, a cooling system, measurement systems, and control units. The annular tube part, which was $160 \mathrm{~cm}$ in length, comprised two tubes; the inner tube was made of $\mathrm{Al}$, and the outer tube was of Plexiglas acrylic with circular cross-section ends; the inner diameter of the outer tube was $30 \mathrm{~mm}$, and the outer diameter of the inner tube was $18 \mathrm{~mm}$. Using Plexiglas with low thermal conductivity (approximately $0.19 \mathrm{~W} /(\mathrm{m} \cdot \mathrm{K}))$ in addition to decreasing the heat dissipation causes the flow regime to be observable in the test section. To provide inner uniform heat flux, an electrical element in length of $100 \mathrm{~cm}$ and a maximum power of $3 \mathrm{~kW}$ was placed inside the inner tube, and its DC power supply was controlled by a Variac. The first $55 \mathrm{~cm}$ of the tube without heat flux was assumed as the entrance length to create hydrodynamic fully developed conditions in the fluid.

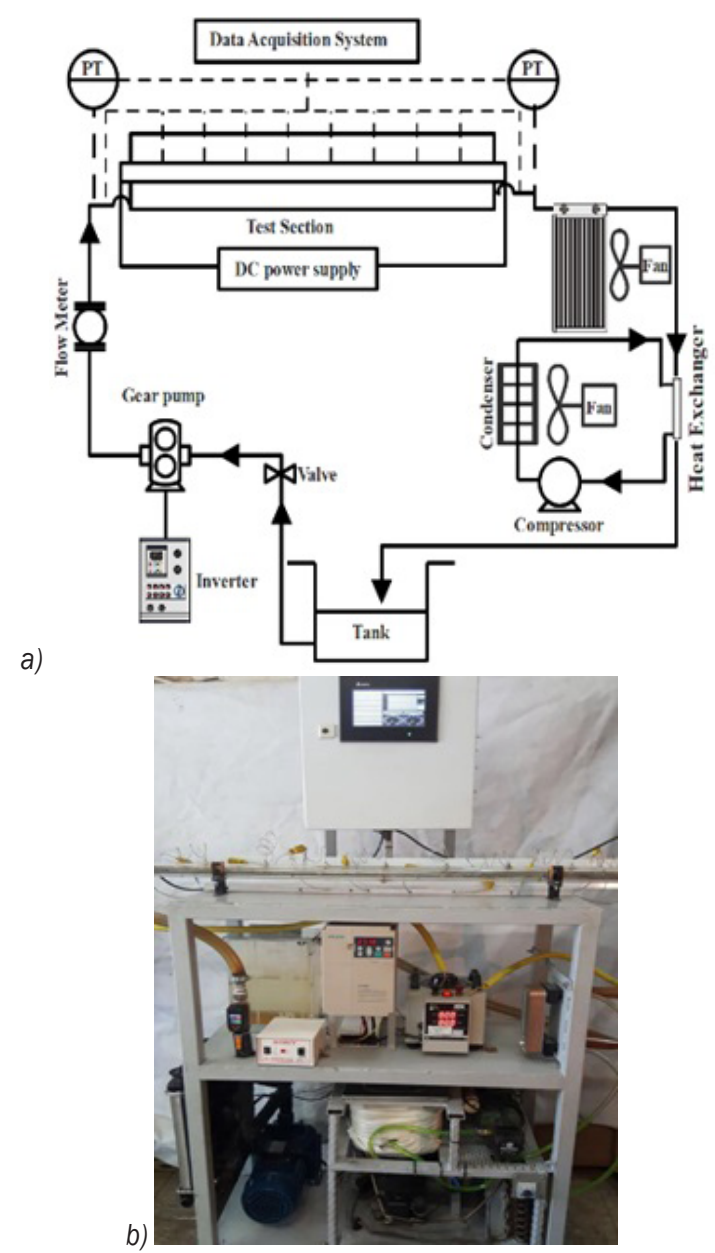

Fig. 5. The experimental setup designed to measure the convective heat transfer; a) schematic illustration of the experimental setup, b) experimental setup

To measure the temperature, 10 K-type thermocouples with the accuracy of $0.1{ }^{\circ} \mathrm{C}$ were used; two were installed in entrance and outlet of the annular tube, and the remaining eight thermocouples were located over the outer surface of the inner tube in equal distances from each other. To minimize the thermal loss along the axial direction, the upstream and downstream parts of the setup were thermally insulated with thick Teflon buffers. Moreover, to indicate the decrease in thermal loss, the external surface of the tube was also thoroughly insulated. A vortex flow-meter (IFM, SV7204, Germany) was employed to measure the total fluid flow, and its value could be adjusted by changing the electromotor frequency of the pump with an inverter. The cooling system was composed of two parts: pre-cooling and cooling. The temperature of the output flow of the annular tube was reduced by a fan in pre-cooling part to reach ambient temperature, and in the cooling 
part by using a plate heat exchanger and through controlling the temperature of the cold container, the temperature was reduced to the required level. In the current experiments, the temperature of the cold container is adjusted to keep the temperature of the inlet flow to the annular tube constant at $25^{\circ} \mathrm{C}$. The pressure of the outlet and inlet flows of the test section was recorded by two pressure transmitter. The experiments were performed in a steady state, and all measurements were carried out, recorded, and shown using a programmable logic controller (PLC).

\subsection{Data Analysis and Validation}

As the fluid flow is in the developing region, it can be stated that the heat transfer coefficient is a function of the axial position along the length of the test section $(z)$ and, according to Eq. (2), it can be written in terms of the ratio of heat flux density ( $q$ ") and temperature gradient between the outside wall temperature of the inner tube $\left(T_{w i}\right)$ and the fluid temperature $\left(T_{f}\right)$ at each section $(z)$.

$$
h_{z}=\frac{q^{\prime \prime}}{T_{w i}(z)-T_{f}(z)} .
$$

The inner wall heat flux $(q ")$ is defined as in which the heat transfer rate $(q)$ is equal to power the of the element and can be measured as $q=V \cdot I$. Through experimental measurements, while considering uniform heat flux in the wall of the inner tube, we could measure the temperature of the inner tube $\left(T_{w i}\right)$ at each section $(z)$, and the fluid temperature $\left(T_{f}\right)$ at each section is calculated from Eq. (3):

$$
T_{f}(z)=T_{f i}+\left(T_{f o}-T_{f i}\right) \frac{z}{L},
$$

where $T_{f i}$ and $T_{f o}$ are the fluid temperatures at the entrance and exit of the test section, which have been recorded by the installed thermocouples. In this research, as the surface temperature was measured at eight equidistant points, the average heat transfer coefficient was calculated as $h=\left(\sum_{j=1}^{8} h_{z_{i}}\right) / 8$ [34]. Furthermore, considering the non-Newtonian effects of the samples, the Reynolds number for the power law fluids can be expressed as Eq. (4) [35]:

$$
R e=\rho U^{2-n} D_{h} / m .
$$

In this equation, the hydraulic diameter of the annulus tube is defined as $D_{h}=d_{o}-d_{i}$, and $U$ refers to flow velocity and was measured by Eq. (5) in which the volume flow rate is denoted by $\dot{V}$ and measured by the flow meter. In this equation, $A_{\text {ann }}$ refers to annulus cross section area.

$$
U=\frac{\dot{V}}{A_{a n n}}=\frac{4}{\pi} \cdot \frac{\dot{V}}{d_{o}^{2}-d_{i}^{2}} .
$$

For validation of experimental results, some experiments were initially executed for DI water, the and results were compared with the Gnielinski correlation, as follows [36]:

$$
N u=\frac{\left(\frac{f_{a n n}}{8}\right) \operatorname{RePr}}{k_{1}+12.7 \sqrt{\frac{f_{\text {ann }}}{8}}\left(\operatorname{Pr}^{\frac{2}{3}}-1\right)}\left[1+\left(\frac{D_{h}}{L}\right)^{\frac{2}{3}}\right] F_{a n n} K,
$$

in which $k_{1}=1.07+900 / \operatorname{Re}-0.63 /(1+10 \cdot P r)$ and for range of $0.1 \leq \operatorname{Pr} \leq 1000,\left(D_{h} / L\right) \leq 1$ and $\operatorname{Re}>4000$. The friction factor of the annulus $\left(f_{a n n}\right)$ depends on the annular diameter ratio $a=\left(d_{i} / d_{o}\right)$ and is calculated from Eq. (7) [37].

$$
f_{\text {ann }}=\left(1.8 \log R e^{*}-1.5\right)^{-2},
$$

where $\operatorname{Re}^{*}=\operatorname{Re} \frac{\left(1+a^{2}\right) \ln a+(1-a)^{2}}{\left(1-a^{2}\right) \ln a}$.

The factor $F_{a n n}$ represents the different boundary conditions and for the boundary condition of heat transfer at the inner wall with the insulated outer wall can be written as $F_{a n n}=\left(0.9-0.15 a^{0.6}\right)$. For liquids, the variation of fluid properties with temperature can be taken into account by using $\mathrm{K}=\left(P r_{b} / P r_{w}\right)^{0.11}$, where $\operatorname{Pr}_{b}$ and $\operatorname{Pr}_{w}$ exhibit the Prandtl numbers of fluid at bulk temperature and at wall temperature, respectively [37].

Table 2 gives the experimental results and values calculated from Eqs. (6) and (7) at six different Reynolds numbers for $D I$ water. In this calculation, the power of the element was kept constant as 2500 $\mathrm{W}$, and the fluid temperature in the entrance to the test section was maintained at $25{ }^{\circ} \mathrm{C}$. In addition, the Nusselt number is defined as Eq. (8):

$$
N u=\frac{h D_{h}}{k},
$$

All thermophysical properties of $D I$ water at mean fluid temperature, $T_{m f}=\left(T_{f i}+T_{f o}\right) / 2$ have been derived from standard references [38]. The values of relative deviation in this table show that the results are acceptable by considering error limits less than $7 \%$ and $11 \%$ for the Nusselt number and friction factor, 
respectively, and this setup can be used for measuring the heat transfer coefficients of nanoporous graphene nanofluids.

Table 2. Comparison of experimental results and Gnielinski correlation for DI water

\begin{tabular}{lcccccc}
\hline $\begin{array}{l}\text { Reynolds } \\
\text { Number }\end{array}$ & 4085 & 5529 & 7010 & 8415 & 10119 & 11410 \\
\hline $\begin{array}{l}\text { Nusselt } \\
\text { by Eq. (6) }\end{array}$ & 37 & 46 & 55 & 64 & 74 & 81 \\
\hline $\begin{array}{l}\text { Nusselt in } \\
\text { present study }\end{array}$ & 39 & 49 & 57 & 68 & 77 & 86 \\
\hline $\begin{array}{l}\text { Relative } \\
\text { deviation [\%] }\end{array}$ & 5.41 & 6.52 & 3.64 & 6.25 & 4.05 & 6.17 \\
\hline $\begin{array}{l}\text { Friction factor } \\
\text { by Eq. (7) }\end{array}$ & 0.045 & 0.041 & 0.038 & 0.036 & 0.034 & 0.033 \\
\hline $\begin{array}{l}\text { Friction factor in } \\
\text { present study }\end{array}$ & 0.049 & 0.045 & 0.041 & 0.039 & 0.037 & 0.036 \\
\hline $\begin{array}{l}\text { Relative } \\
\text { deviation [\%] }\end{array}$ & 7.65 & 9.75 & 8.04 & 9.83 & 10.16 & 9.73 \\
\hline
\end{tabular}

\section{RESULTS AND DISCUSSION}

The local heat transfer coefficient of the base fluid and the nanofluids prepared with nanoporous graphene with three different concentrations at $R e$ of 4000 and at a constant heat transfer rate of $2500 \mathrm{~W}$ were compared, and the results are displayed in Fig. 6a. Considering the location of the sensors, the local heat transfer coefficient could be recorded at eight sections. The local heat transfer coefficients of all samples, by developing the thermal boundary layer along the annular tube, was reduced to a constant value. With the decrease in heat transfer coefficient and the augment of the fluid temperature at the constant heat flux, the heat transfer to fluid was reduced, and the wall temperature increased (Fig. 6b). The wall temperature values in Fig. 6b indicate high-temperature gradients at the beginning of the thermal region, the intensity of which was reduced by decreasing the local heat transfer coefficient along the length of the tube.

The results revealed that by using the nanoporous graphene in concentrations of 0.05 wt. $\%, 0.1$ wt. $\%$, and 0.2 wt. $\%$, the average heat transfer coefficient was enhanced by $16.3 \%, 30.8 \%$, and $39.8 \%$, respectively, compared to that of the base fluid which in turn led to $5.7 \%, 9.8 \%$, and $16 \%$ decrease in average wall temperature. In Fig. 7, the improvement percentage of heat transfer coefficient in comparison to that of thermal conductivity is plotted in terms of nanoparticle concentration. This curve implies that the improvement of heat transfer coefficient observed for the samples was higher than the mere contribution of thermal conductivity. So it is deduced that other factors influence the convective heat transfer of the nanofluids. The base solution and also the nanofluids prepared by employing nanoporous graphene displayed pseudo-plastic behaviour which means that by increasing the shear rate, apparent viscosity is decreased. Because the shear rate is higher in the vicinity of the tube wall, the apparent viscosity is lower at those regions. This leads to a decrease in thickness of the boundary layer and increment of the heat transfer rate. Furthermore, the nanoparticles dispersed in the fluid are moved from the region with a high shear rate to regions with a low shear rate. Consequently, near the wall, nanoparticle concentration is decreased, leading to lower apparent viscosity and, as a result, a thinner boundary layer is obtained [39] and [40].

Additionally, thermal dispersion as a result of random motion of the nanoparticles can also affect this enhancement and thus flatten the temperature profile. Altogether, a steeper temperature gradient
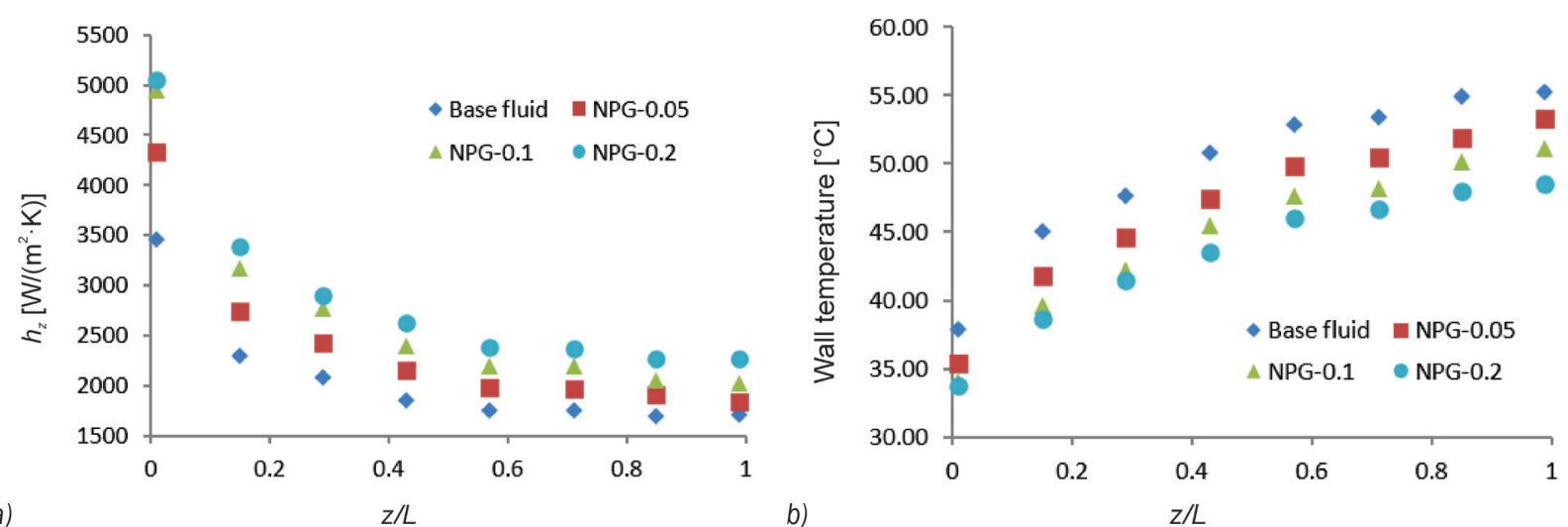

Fig. 6. a) The local heat transfer coefficient; b) wall temperature for different samples at Reynolds 4000 
is observed at the wall, and the heat transfer rate is augmented there. There are also other factors including the collision of nanoparticles and probable slip velocity at boundaries, which may be the reason for the improvement of the heat transfer coefficient [41].

In contrast, as it is clear in Fig. 7, up to a concentration of $0.1 \mathrm{wt} . \%$, this enhancement showed an almost a linear trend; however, after that, the rate of these changes with concentration was decreased. As the conductivity of the nanofluids is highly dependent on the stability of the particles in the base fluid, it seems that the decrease in the rate of enhancement is due to the deterioration of stability and reaches the threshold of nanoporous graphene deposition in the base fluid at higher concentrations [42].

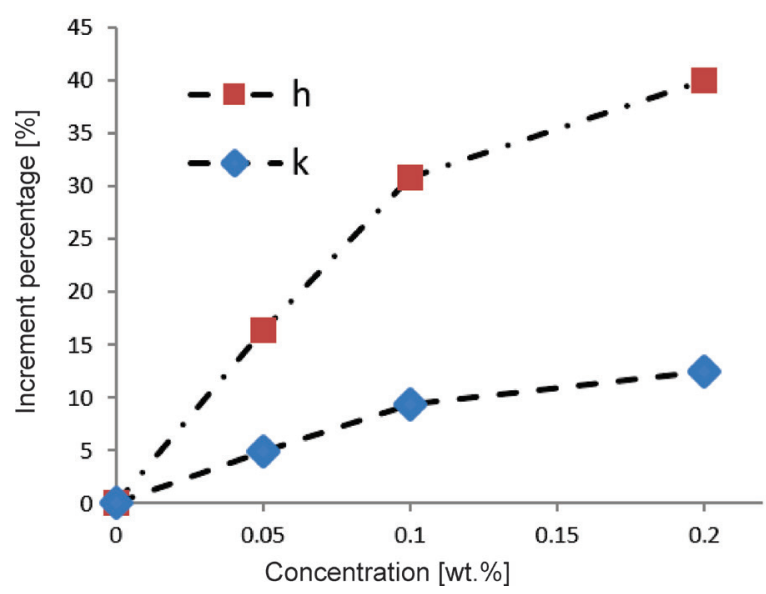

Fig. 7. Heat transfer coefficient and thermal conductivity increment with a concentration of nanoporous graphene

By maintaining the inlet temperature and wall heat flux constant, the above experiments were repeated for all samples at different Reynolds numbers. The changes of local heat transfer coefficient and wall temperature in terms of dimensionless length for nanofluid with a concentration of $0.2 \mathrm{wt} . \%$ at different Reynolds numbers in the range of 4,000 to 11,500 are plotted in Fig. 8a. As expected, by increasing the Reynolds number, the local heat transfer coefficient was increased, and the relative wall temperature was decreased (Fig. 8b). The results indicate a $119 \%$ increase of the average heat transfer coefficient and a $20.4 \%$ decrease in average wall temperature while increasing the Reynolds number from 4,000 to 11,500.

The average heat transfer coefficient as a function of the Reynolds number for base fluid and different nanoparticle concentrations is presented in Fig. 9. It was also observed that using nanoporous graphene could lead to a significant increase in heat transfer coefficient in all Reynolds number ranges. This increase was almost independent of Reynolds number and on average was obtained to be $16.1 \%$, $30.3 \%$, and $39.4 \%$ for the NPG-0.05, NPG-0.1, and NPG-0.2 samples, respectively. However, as explained previously, this rate of increase was reduced by increasing the concentration to higher levels. By increasing the Reynolds number, the heat transfer coefficients of all samples were increased roughly linearly.

Regarding the Nusselt number of the samples, a similar trend was again observed, the results of which are exhibited in Fig. 10. Using nanoporous graphene in concentration of 0.2 wt. $\%$, augmented the Nusselt number by $19.2 \%$ on average compared to that of the base solution. Most of this increase was up to concentration of $0.1 \mathrm{wt} . \%$ and, by doubling the nanoparticles content from $0.1 \mathrm{wt} \% \%$ to $0.2 \mathrm{wt} . \%$, only a negligible increase in Nusselt number was seen (less than $4 \%$ ).
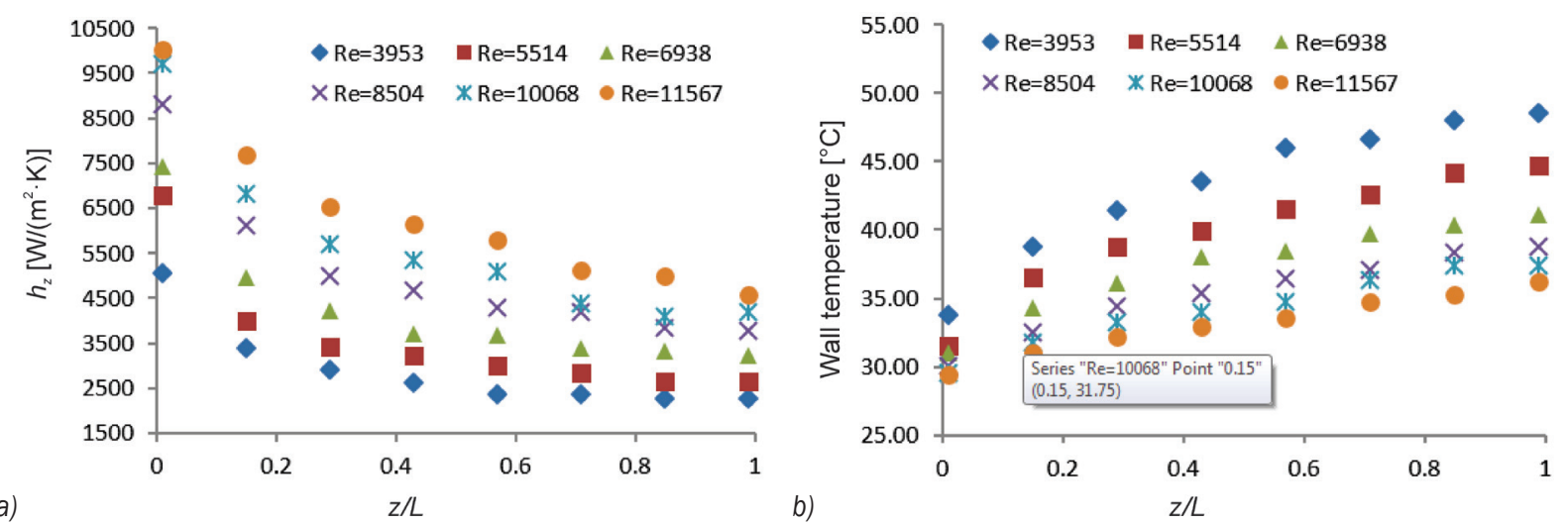

Fig. 8. a) The local heat transfer coefficient; b) wall temperature at different Reynolds numbers for NPG-0.2 


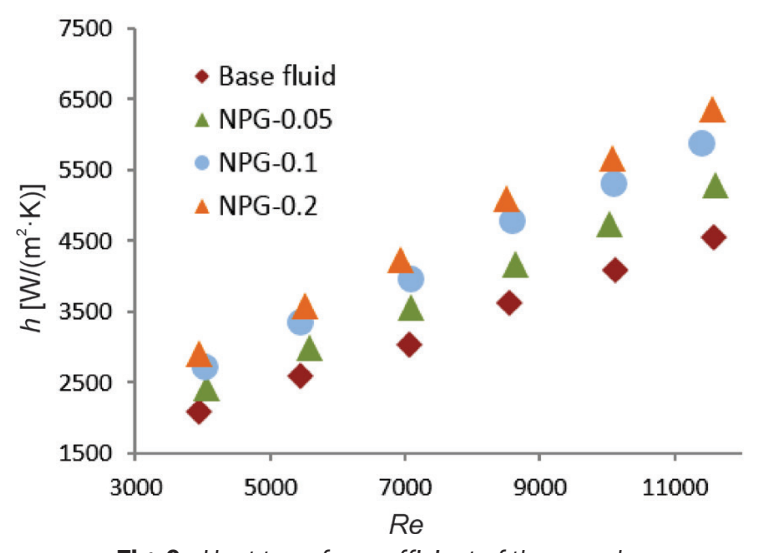

Fig. 9. Heat transfer coefficient of the samples at different Reynolds numbers

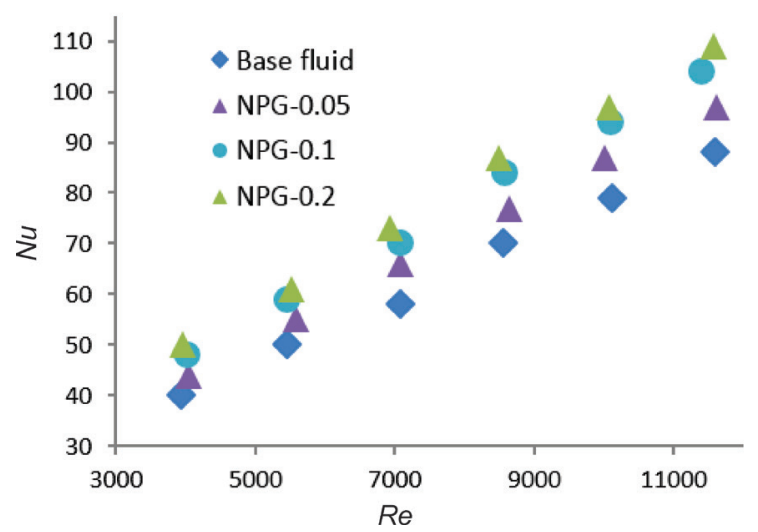

Fig. 10. Nusselt number of the samples at different Reynolds numbers

The pressure drop $(\Delta P)$ along the length of the test section for the base solution and the nanofluids was also investigated at all Reynolds numbers, and their results are presented in Table 3. As the measurements indicate, by increasing the Reynolds number and the nanoparticle concentration in the base solution, the pressure drop was increased.

Table 3. The pressure drop values of the samples in $\mathrm{kPa}$ at different Reynolds number

\begin{tabular}{lcccccc}
\hline $\begin{array}{l}\text { Reynolds } \\
\text { number }\end{array}$ & 4000 & 5500 & 7000 & 8500 & 10000 & 11500 \\
\hline Base fluid & 0.52 & 0.83 & 1.20 & 1.63 & 2.13 & 2.70 \\
\hline NPG-0.05 & 0.62 & 0.93 & 1.41 & 1.80 & 2.27 & 2.87 \\
\hline NPG-0.1 & 0.67 & 1.00 & 1.46 & 1.97 & 2.49 & 2.94 \\
\hline NPG-0.2 & 0.91 & 1.35 & 1.93 & 2.66 & 3.23 & 4.02 \\
\hline
\end{tabular}

By taking into account both heat transfer performance and flow resistance characteristics, to assess the performance of the heat exchanger, the thermal performance factor (TPF) can be employed, which is obtained through Eq. (9) [43]:

$$
T P F=\frac{\frac{N u_{n f}}{N u_{b f}}}{\left(\frac{f_{n f}}{f_{b f}}\right)^{\frac{1}{3}}},
$$

where, " $n f$ " and " $b f$ " refer to the nanofluid and base fluid, respectively. Moreover, considering flow velocity $(U)$ and the pressure drop $(\Delta P)$, the friction factor $(f)$ can be calculated through Eq. (10):

$$
f=\frac{\Delta P}{\frac{1}{2} \rho U^{2}\left(\frac{L}{D_{h}}\right)} .
$$

It can be stated that the $T P F$ values that are higher than 1 contribute to improved integrative performance of the nanofluid compared to the base fluid; so, higher values of TPF are preferable. Fig. 11 depicts the variation trend of TPF values as a function of the Reynolds number. From this figure, it is clear that the $T P F$ values of all the nanofluid samples with different concentrations of nanoparticles were higher than 1 .

In comparison to the base fluid, the overall performance of all samples including $N P G-0.05, N P G$ 0.1 , and $N P G-0.2$, on average was enhanced by about $8.7 \%, 16.7 \%$, and $14.2 \%$, respectively. It should be noted that increasing the concentration of nanoporous graphene nanoparticles from $0.1 \mathrm{wt} \%$ to $0.2 \mathrm{wt} . \%$ did not increase the overall thermal performance; furthermore, regarding the induced pressure drop in the system, this increase in concentration decreased the overall thermal performance. Consequently, in the preparation of nanoporous graphene nanofluids, the optimum concentration is $0.1 \mathrm{wt} . \%$, which can be employed in further studies.

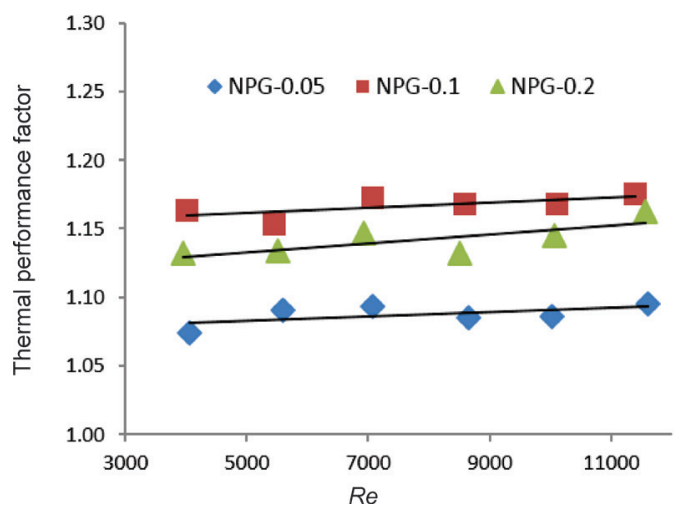

Fig. 11. Thermal performance factor vs Reynolds number for the prepared nanofluids 


\section{CONCLUSION}

In this research work, nanoporous graphene nanoparticles were used to prepare nanofluids with enhanced thermal performance. The results obtained from using these non-Newtonian nanofluids flowing through a horizontal annular tube are presented. The boundary condition was set as "constant heat flux at the inner wall with the outer wall insulated". To prepare the nanofluids, different concentrations of nanoporous graphene including 0.05 wt.\%, 0.1 wt.\%, and 0.2 wt. $\%$ were dispersed in aqueous solution of $C M C$. The nanofluids which were formed by using 0.2 wt.\% $C M C$ as surfactant and using ultrasonic system for $4 \mathrm{~h}$, were of a good stability. The results revealed that addition of $0.05 \mathrm{wt} . \%, 0.1 \mathrm{wt} \%$, and 0.2 wt.\% nanoporous graphene to the base solution increased the heat transfer coefficient by $16.1 \%$, $30.3 \%$, and $39.4 \%$, respectively, this improvement up to concentration of 0.1 wt. $\%$ was almost linear, after which rate of increase was appreciably lowered. Decrease in increase rate of the heat transfer coefficient at higher concentrations and also the effects of saturation, sedimentation, and increase in pressure drop of the non-Newtonian fluid led to the fact that doubling the concentration from $0.1 \mathrm{wt} . \%$ to $0.2 \mathrm{wt} . \%$ not only did not enhance the thermal performance but also decreased it by about $2.5 \%$. These measurements showed that in an annular tube, although at a given Reynolds number the heat transfer coefficient of the nanofluid with 0.2 wt. $\%$ nanoparticles in average is $9.1 \%$ higher than that of the sample with 0.1 wt. $\%$ nanoparticles, considering the pressure drop and energy consumption, using the nanofluid of $0.1 \mathrm{wt} . \%$ is more preferable, which is the optimum content of nanoporous graphene in preparation of the nanofluid.

\section{NOMENCLATURE}

a annular diameter ratio $d_{i} / d_{o}$,

$A \quad$ area, $\left[\mathrm{m}^{2}\right]$

$c_{p} \quad$ heat capacity, $[\mathrm{J} /(\mathrm{kg} \cdot \mathrm{K})]$

$d \quad$ diameter, [m]

$D_{h} \quad$ hydraulic diameter, [m]

$f \quad$ friction factor, [-]

$F \quad$ a factor to take into account the dependence on $d_{i} / d_{o}$,

$h \quad$ heat transfer coefficient, $\left[\mathrm{W} /\left(\mathrm{m}^{2} \cdot \mathrm{K}\right)\right]$

I electrical current, [A]

$k \quad$ thermal conductivity, $[\mathrm{W} /(\mathrm{m} \cdot \mathrm{K})]$

$K \quad$ a factor to take into account the temperature dependence of fluid properties, [-]

$k_{1} \quad$ a factor, [-]
$L \quad$ length of annular tube, $[\mathrm{m}]$

$m$ flow consistency index, [-]

$n \quad$ flow behavior index, [-]

$\mathrm{Nu} \quad$ Nusselt number, [-]

$P$ pressure, $[\mathrm{Pa}]$

Pr Prandtl number, [-]

$q \quad$ heat transfer rate, [W]

$q " \quad$ heat flux, [W/m²]

Re Reynolds number, [-]

$R e^{*} \quad$ modified Reynolds number, [-]

$T$ temperature, $\left[{ }^{\circ} \mathrm{C}\right]$

TPF thermal performance factor, [-]

$U$ flow velocity, $[\mathrm{m} / \mathrm{s}]$

$V \quad$ voltage, [V]

$\dot{V} \quad$ volume flow rate, $\left[\mathrm{m}^{3} / \mathrm{s}\right]$

$X \quad$ each measured value,

$z \quad z$-axis,

Greek symbols:

$\rho$ density, $\left[\mathrm{kg} / \mathrm{m}^{3}\right]$

$\eta \quad$ apparent viscosity, $[\mathrm{Pa} \cdot \mathrm{s}]$

$\sigma \quad$ uncertainty of measurement, [\%]

$\Delta \quad$ difference, [-]

$\gamma \quad$ shear rate, $[1 / \mathrm{s}]$

Subscripts:

ann annulus

$b \quad$ bulk

bf base fluid

$f \quad$ fluid

$f i \quad$ fluid at entrance of test section

fo fluid at exit of the test section

$i \quad$ inner tube

$m f \quad$ mean fluid

$n f \quad$ nanofluid

$i$, $o \quad$ inner tube, outer tube

w wall

wi wall of inner tube

$z \quad$ axial position along the length of annular tube $[\mathrm{m}]$

\section{APPENDIX: UNCERTAINITY ANALYSIS}

All values $(X)$ which have been measured include uncertainty of measurement $(\delta X)$ which can be given as follows:

$$
X=X_{\text {measured }} \pm \delta X
$$

The accuracy of the instruments used for measuring in this study is given in Table 4. 
Table 4. The accuracy of the instruments

\begin{tabular}{lcc}
\hline Instrument & Variable & Accuracy \\
\hline Calipers & $d_{i}, d_{o}, D_{h}$ & $\pm 0.0001 \mathrm{~m}$ \\
\hline Densitometer & $\rho$ & $\pm 0.1\left[\mathrm{~kg} / \mathrm{m}^{3}\right]$ \\
\hline KD2 Pro & $k$ & $\pm 5 \%$ \\
\hline K-type Thermocouples & $T_{w i}, T_{f}$ & $\pm 0.1^{\circ} \mathrm{C}$ \\
\hline Meter & $L$ & $\pm 0.001 \mathrm{~m}$ \\
\hline Pressure transmitter & $\Delta P$ & $\pm 2 \%$ \\
\hline Variac & $V$ & $\pm 1 \mathrm{~V}$ \\
\hline Variac & $I$ & $\pm 0.1 \mathrm{~A}$ \\
\hline Vortex flow meter & $\dot{V}$ & $\pm 2 \%$ \\
\hline
\end{tabular}

To calculate the uncertainty of a dependent parameter $\varphi=f\left(X_{1}, \ldots, X_{j}\right)$, the Kline and McClintock model through the root sum square method has been employed [21]:

$$
\delta \varphi=\sqrt{\sum_{i=1}^{j}\left(\frac{\partial \varphi}{\partial X_{i}} \delta X_{i}\right)^{2}} .
$$

In this regard, for the Nusselt number we have:

$$
\frac{\delta N u}{N u}=\left[\left(\left(\frac{\delta h}{h}\right)^{2}+\left(\frac{\delta D_{h}}{D_{h}}\right)^{2}+\left(\frac{\delta k}{k}\right)^{2}\right)\right]^{\frac{1}{2}},
$$

where:

$$
\frac{\delta h}{h}=\left[\begin{array}{l}
\left(\frac{\delta V}{V}\right)^{2}+\left(\frac{\delta I}{I}\right)^{2}+\left(\frac{\delta d_{i}}{d_{i}}\right)^{2}+\left(\frac{\delta L}{L}\right)^{2}+ \\
+\left(\frac{\delta T_{w i}}{T_{w i}-T_{f}}\right)^{2}+\left(\frac{\delta T_{f}}{T_{w i}-T_{f}}\right)^{2}
\end{array}\right]^{\frac{1}{2}},
$$

and for the friction factor is as follows:

$$
\frac{\delta f}{f}=\left[\begin{array}{l}
\left(\frac{\delta \Delta p}{\Delta p}\right)^{2}+\left(\frac{\delta D_{h}}{D_{h}}\right)^{2}+\left(\frac{\delta \rho}{\rho}\right)^{2}+ \\
+\left(\frac{\delta L}{L}\right)^{2}+\left(\frac{2 \delta U}{U}\right)^{2}
\end{array}\right],
$$

where:

$$
\frac{\delta U}{U}=\left[\left(\left(\frac{\delta \dot{V}}{\dot{V}}\right)^{2}+\left(\frac{2 d_{o} \delta d_{o}}{d_{o}^{2}-d_{i}^{2}}\right)^{2}+\left(\frac{2 d_{i} \delta d_{i}}{d_{o}^{2}-d_{i}^{2}}\right)^{2}\right)\right]^{\frac{1}{2}} .
$$

The maximum uncertainties of heat transfer coefficient $(h)$, Nusselt number $(\mathrm{Nu})$ and friction factor $(f)$ were calculated as $2.3 \%, 5.5 \%$ and $3.1 \%$, respectively.

\section{REFERENCES}

[1] Moreira, T.A., Moreira, D.C., Ribatski, G. (2018). Nanofluids for heat transfer applications: a review. Journal of the Brazilian Society of Mechanical Sciences and Engineering, vol. 40, no. 303, DOI:10.1007/s40430-018-1225-2.

[2] Pinto, R.V., Fiorelli, F.A.S. (2016). Review of the mechanisms responsible for heat transfer enhancement using nanofluids. Applied Thermal Engineering, vol. 108, p. 720-739, DOl:10.1016/j.applthermaleng.2016.07.147.

[3] Öztürk, A., Kahveci, K. (2016). Slip flow of nanofluids between parallel plates heated with a constant heat flux. Strojniški vestnik - Journal of Mechanical Engineering, vol. 62, no. 9, p. 511-520, DOl:10.5545/sv-jme.2016.3188.

[4] Keblinski, P., Eastman, J.A., Cahill, D.G. (2005). Nanofluids for thermal transport. Materials today, vol. 8, no. 6, p. 36-44, DOI:10.1016/S1369-7021(05)70936-6.

[5] Heris, S.Z., Esfahany, M.N., Etemad, S.G. (2007). Experimental investigation of convective heat transfer of $\mathrm{Al}_{2} \mathrm{O}_{3}$ /water nanofluid in circular tube. International Journal of Heat and Fluid Flow, vol. 28, no. 2, p. 203-210, Dol:10.1016/j. ijheatfluidflow.2006.05.001.

[6] Patel, H.E., Das, S.K., Sundararajan, T., Sreekumaran Nair, A., George, B., Pradeep, T. (2003). Thermal conductivities of naked and monolayer protected metal nanoparticle based nanofluids: Manifestation of anomalous enhancement and chemical effects. Applied Physics Letters, vol. 83, no. 14, p. 2931-2933, DOl:10.1063/1.1602578.

[7] Zarringhalam, M., Karimipour, A., Toghraie, D. (2016). Experimental study of the effect of solid volume fraction and Reynolds number on heat transfer coefficient and pressure drop of CuO-water nanofluid. Experimental Thermal and Fluid Science, vol. 76, p. 342-351, D0l:10.1016/j. expthermflusci.2016.03.026.

[8] Kakaç, S., Pramuanjaroenkij, A. (2009). Review of convective heat transfer enhancement with nanofluids. International Journal of Heat and Mass Transfer, vol. 52, no. 13-14, p. 3187-3196, D0I:10.1016/j.ijheatmasstransfer.2009.02.006.

[9] Sidik, N.A.C., Mohammed, H.A., Alawi, O.A., Samion, S. (2014). A review on preparation methods and challenges of nanofluids. International Communications in Heat and Mass Transfer, vol. 54, p. 115-125, D0l:10.1016/j. icheatmasstransfer.2014.03.002.

[10] Raja, M., Vijayan, R., Dineshkumar, P., Venkatesan, M. (2016). Review on nanofluids characterization, heat transfer characteristics and applications. Renewable and Sustainable Energy Reviews, vol. 64, p. 163-173, D0l:10.1016/j. rser.2016.05.079.

[11] Taamneh, Y., Bataineh, K. (2017). Mixed convection heat transfer in a square lid-driven cavity filled with $\mathrm{Al}_{2} \mathrm{O}_{3}$ water nanofluid. Strojniški vestnik - Journal of Mechanical Engineering, vol. 63, no. 6, p. 383-393, D0I:10.5545/svjme.2017.4449.

[12] Al-Kouz, W.G., Kiwan, S., Alkhalidi, A., Sari, M., Alshare, A. (2018). Numerical study of heat transfer enhancement for low-pressure flows in a square cavity with two fins attached to the hot wall using $\mathrm{Al}_{2} \mathrm{O}_{3}$-air nanofluid. Strojniški vestnik - 
Journal of Mechanical Engineering, vol. 64, no. 1, p. 26-36, DOI:10.5545/sv-jme.2017.4989.

[13] Vahidinia, F., Miri, M. (2015). Numerical study of the effect of the Reynolds numbers on thermal and hydrodynamic parameters of turbulent flow mixed convection heat transfer in an inclined tube. Strojniški vestnik - Journal of Mechanical Engineering, vol. 61, no. 11, p. 669-679, Dol:10.5545/svjme.2015.2818.

[14] Mishra, R., Militky, J. (2019). Carbon-based nanomaterials. Nanotechnology in Textiles, vol. 2019, p. 163-179, DOI:10.1016/B978-0-08-102609-0.00003-1.

[15] Teng, T.-P., Hsiao, T.-C., Chung, C.-C. (2019). Characteristics of carbon-based nanofluids and their application in a brazed plate heat exchanger under laminar flow. Applied Thermal Engineering, vol. 146, p. 160-168, D0l:10.1016/j. applthermaleng.2018.09.125.

[16] Amrollahi, A., Rashidi, A.M., Lotfi, R., Meibodi, M.E., Kashefi, K. (2010). Convection heat transfer of functionalized MWNT in aqueous fluids in laminar and turbulent flow at the entrance region. International Communications in Heat and Mass Transfer, vol. 37, no. 6, p. 717-723, D0l:10.1016/j. icheatmasstransfer.2010.03.003.

[17] Naghash, A., Sattari, S., Rashidi, A. (2016). Experimental assessment of convective heat transfer coefficient enhancement of nanofluids prepared from high surface area nanoporous graphene. International Communications in Heat and Mass Transfer, vol. 78, p. 127-134, D0l:10.1016/j. icheatmasstransfer.2016.09.004.

[18] Amiri, A., Arzani, H.K., Kazi, S.N., Chew, B.T., Badarudin, A. (2016). Backward-facing step heat transfer of the turbulent regime for functionalized graphene nanoplatelets based water-ethylene glycol nanofluids. International Journal of Heat and Mass Transfer, vol. 97, p. 538-546, D0l:10.1016/j. ijheatmasstransfer.2016.02.042.

[19] Askari, S., Lotfi, R., Seifkordi, A., Rashidi, A. M., Koolivand, H. (2016). A novel approach for energy and water conservation in wet cooling towers by using MWNTs and nanoporous graphene nanofluids. Energy Conversion and Management, vol. 109, p. 10-18, D0I:10.1016/J.enconman.2015.11.053.

[20] Ranjbarzadeh, R., Karimipour, A., Afrand, M., Isfahani, A.H.M., Shirneshan, A. (2017). Empirical analysis of heat transfer and friction factor of water/graphene oxide nanofluid flow in turbulent regime through an isothermal pipe. Applied Thermal Engineering, vol. 126, p. 538-547, D0l:10.1016/j. applthermaleng.2017.07.189.

[21] Taheran, E., Javaherdeh, K. (2019). Experimental investigation on the effect of inlet swirl generator on heat transfer and pressure drop of non-Newtonian nanofluid. Applied Thermal Engineering, vol. 147, p. 551-561, D0l:10.1016/j. applthermaleng.2018.07.12.

[22] Behroyan, I., Vanaki, Sh. M., Ganesan, P., Saidur, R. (2016). A comprehensive comparison of various CFD models for convective heat transfer of $\mathrm{Al}_{2} \mathrm{O}_{3}$ nanofluid inside a heated tube. International Communications in Heat and Mass Transfer, vol. 70, p. 27-37, D0l:10.1016/j. icheatmasstransfer.2015.11.001.

[23] Hojjat, M., Etemad, S.Gh., Bagheri, R., Thibault, J. (2011). Rheological characteristics of non-Newtonian nanofluids: experimental investigation. International Communications in Heat and Mass Transfer, vol. 38, no. 2, p. 144-148, DOI:10.1016/j.icheatmasstransfer.2010.11.019.

[24] Kole, M., Dey, T.K. (2011). Effect of aggregation on the viscosity of copper oxide-gear oil nanofluids. International Journal of Thermal Sciences, vol. 50, no. 9, p. 1741-1747, D0l:10.1016/j.ijthermalsci.2011.03.027.

[25] Togun, H., Abdulrazzaq, T., Kazi, S.N., Badarudin, A., Kadhum, A.A.H., Sadeghinezhad, E. (2014). A review of studies on forced, natural and mixed heat transfer to fluid and nanofluid flow in an annular passage. Renewable and Sustainable Energy Reviews, vol. 39, p. 835-856, D0l:10.1016/j. rser.2014.07.008.

[26] Bahiraei, M., Khosravi, R., Heshmatian, S. (2017). Assessment and optimization of hydrothermal characteristics for a nonNewtonian nanofluid flow within miniaturized concentric-tube heat exchanger considering designer's viewpoint. Applied Thermal Engineering, vol. 123, p. 266-276, Dol:10.1016/j. applthermaleng.2017.05.090.

[27] Latifa, E.-K., Asbik, M., Zari, N., Zeghmati, B. (2017). Experimental study of the sensible heat storage in the water/TiO2 nanofluid enclosed in an annular space. Applied Thermal Engineering, vol. 122, p. 673-684, D0l:10.1016/j. applthermaleng.2017.05.054.

[28] Arzani, H.K., Amiri, A., Kazi, S.N., Chew, B.T., Badarudin, A. (2016). Experimental investigation of thermophysical properties and heat transfer rate of covalently functionalized MWCNT in an annular heat exchanger. International Communications in Heat and Mass Transfer, vol. 75, no. 6777, D0I:10.1016/j.icheatmasstransfer.2016.03.015.

[29] Arzani, H.K., Amiri, A., Kazi, S.N., Chew, B.T., Badarudin, A. (2015). Experimental and numerical investigation of thermophysical properties, heat transfer and pressure drop of covalent and noncovalent functionalized graphene nanoplatelet-based water nanofluids in an annular heat exchanger. International Communications in Heat and Mass Transfer, vol. 68, p. 267-275, D0l:10.1016/j. icheatmasstransfer.2015.09.007.

[30] Pourmand, S., Abdouss, M., Rashidi, A. (2015). Fabrication of nanoporous graphene by chemical vapor deposition (CVD) and its application in oil spill removal as a recyclable nanosorbent. Journal of Industrial and Engineering Chemistry, vol. 22, p. 8-18, D0I:10.1016/j.jiec.2014.06.018.

[31] Hojjat, M., Etemad, S.G., Bagheri, R., Thibault, J. (2009). Rheological behavior of non-Newtonian nanofluids. The $6^{\text {th }}$ International Chemical Engineering Congress \& Exhibition.

[32] Li, M. (2013). A nano-graphite/paraffin phase change material with high thermal conductivity. Applied Energy, vol. 106, p. 2530, DOI:10.1016/J.apenergy.2013.01.031.

[33] Estellé, P., Halelfadl, S., Maré, T. (2015). Thermal conductivity of CNT water based nanofluids: Experimental trends and models overview. Journal of Thermal Engineering, vol. 1, no. 2, p. 381-390, DOI:10.13140/2.1.2173.9843.

[34] Kutz, M. (2006). Heat Transfer Calculations. McGraw-Hill, New York.

[35] Crespí-Llorens, D., Vicente, P., Viedma, A. (2015). Generalized Reynolds number and viscosity definitions for nonNewtonian fluid flow in ducts of non-uniform cross-section. 
Experimental Thermal and Fluid Science, vol. 64, p. 125-133, DOI:10.1016/j.expthermflusci.2015.02.005.

[36] Gnielinski, V. (2009). Heat transfer coefficients for turbulent flow in concentric annular ducts. Heat Transfer Engineering, vol. 30, p. 6, no. 431-436, DOl:10.1080/01457630802528661.

[37] Gnielinski, V. (2015). Turbulent heat transfer in annular spaces-a new comprehensive correlation. Heat Transfer Engineering, vol. 36, no. 9, p. 787-789, Dol:10.1080/01457 632.2015.962953.

[38] Bergman, T.L, Lavine, A.S., Incropera, F.P., Dewitt, D.P. (2011). Fundamentals of Heat and Mass Transfer, $7^{\text {th }}$ ed. Thermophysical Properties of Matter, Appendix A, p. 1003, John Wiley \& Sons, Hoboken.

[39] Anoop, K.B., Sundararajan, T., Das, S.K. (2009). Effect of particle size on the convective heat transfer in nanofluid in the developing region. International Journal of Heat and Mass Transfer, vol. 52, no. 9-10, p. 2189-2195, D0l:10.1016/j. ijheatmasstransfer.2007.11.063.
[40] Xuan, Y., Li, Q. (2003). Investigation on convective heat transfer and flow features of nanofluids. Journal of Heat Transfer, vol. 125, no. 1, p. 151-155, Dol:10.1115/1.1532008.

[41] Hojjat, M., Etemad, S.G., Bagheri, R., Thibault, J. (2011). Convective heat transfer of non-Newtonian nanofluids through a uniformly heated circular tube. International Journal of Thermal Sciences, vol. 50, no. 4, p. 525-531, D0I:10.1016/j. ijthermalsci.2010.11.006.

[42] Ghozatloo, A., Rashidi, A., Shariaty-Niassar, M. (2014). Convective heat transfer enhancement of graphene nanofluids in shell and tube heat exchanger. Experimental Thermal and Fluid Science, vol. 53, p. 136-141, D0l:10.1016/j. expthermflusci.2013.11.018.

[43] Maradiya, C., Vadher, J., Agarwal, R. (2018). The heat transfer enhancement techniques and their thermal performance factor. Beni-Suef University Journal of Basic and Applied Sciences, vol. 7, no. 1, p. 1-21, D0l:10.1016/j. bjbas.2017.10.001. 